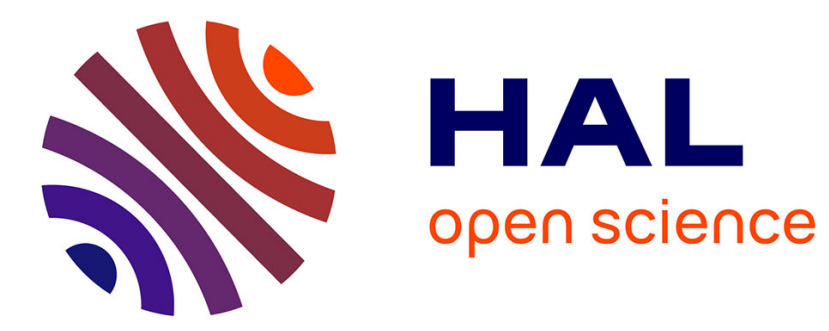

\title{
Novel in situ electrochemical deposition of platinum nanoparticles by sinusoïdal voltages on conducting polymer films.
}

\author{
Stelian Lupun, Boris Lakard, Jean-Yves Hihn, Jérôme Dejeu
}

\section{To cite this version:}

Stelian Lupun, Boris Lakard, Jean-Yves Hihn, Jérôme Dejeu. Novel in situ electrochemical deposition of platinum nanoparticles by sinusoïdal voltages on conducting polymer films.. Synthetic Metals, 2012, 162 (1-2), pp.193-198. hal-00664520

\author{
HAL Id: hal-00664520 \\ https://hal.science/hal-00664520
}

Submitted on 30 Jan 2012

HAL is a multi-disciplinary open access archive for the deposit and dissemination of scientific research documents, whether they are published or not. The documents may come from teaching and research institutions in France or abroad, or from public or private research centers.
L'archive ouverte pluridisciplinaire HAL, est destinée au dépôt et à la diffusion de documents scientifiques de niveau recherche, publiés ou non, émanant des établissements d'enseignement et de recherche français ou étrangers, des laboratoires publics ou privés. 


\title{
Novel in situ electrochemical deposition of platinum nanoparticles by sinusoidal voltages on conducting polymer films
}

Stelian Lupu ${ }^{\mathrm{a}, *}$, Boris Lakard ${ }^{\mathrm{b}}$, Jean-Yves Hihn ${ }^{\mathrm{b}}$, Jérôme Dejeu $^{\mathrm{c}}$

${ }^{a}$ Department of Analytical Chemistry and Instrumental Analysis, Faculty of Applied Chemistry and Materials Science, University Politehnica of Bucharest, Polizu Street 15, 011061 Bucharest, Romania

${ }^{b}$ Institut UTINAM, CNRS-UMR 6213, Université de Franche-Comté, 16 route de Gray, Besançon Cedex 25030, France

${ }^{c}$ Institut FEMTO-ST, CNRS-UFC-ENSMM-UTBM, AS2M Department, 24 rue Alain Savary, 25000 Besançon, France

\begin{abstract}
Platinum (Pt) nanoparticles were successfully electrodeposited in situ on an organic conductive polymer, poly(3,4-ethylenedioxythiophene) (PEDOT), using for the first time sinusoidal voltages of various frequencies in a chloroplatinic acid solution. The organic PEDOT matrix was electrodeposited on Pt electrode chips. The Pt electrode chips consist of a $150 \mathrm{~nm}$ Pt layer deposited on 100-oriented standard 3', silicon wafers. The cyclic voltammograms of the PEDOT-Pt-nanoparticles composite material recorded in $0.5 \mathrm{M} \mathrm{H} \mathrm{H}_{2} \mathrm{SO}_{4}$ aqueous solution demonstrated that $\mathrm{Pt}$ nanoparticles are electrochemically active. Values of the roughness of the composite materials, measured by optical non-contact 3D profilometry, ranging from $880 \mathrm{~nm}$ to $1.6 \mu \mathrm{m}$ were obtained

\footnotetext{
* Corresponding author. Phone: +40 21 4023886; fax: +40 21 3111796, E-mail address:
} stelianl@yahoo.com
\end{abstract}


depending on the time of deposition of the nanoparticles. The PEDOT-Pt-nanoparticles composite deposited by a sinusoidal voltage with a frequency range of $0.1 \mathrm{~Hz}-100$ $\mathrm{kHz}, 50$ frequencies, has the largest active surface area $\left(5.16 \mathrm{~cm}^{2}\right)$ compared with other composite coatings prepared in this work and those previously reported. Atomic force microscopic (AFM) images revealed the presence of numerous deposited $\mathrm{Pt}$ nanoparticles on the organic PEDOT polymer film.

Keywords: Atomic force microscopy, Sinusoidal voltage, Poly(3,4ethylenedioxythiophene), Platinum metal nanoparticles

\section{Introduction}

The preparation of nanoparticles based composite materials has attracted considerable interest due to their applications in electrochemical sensors and biosensors [1-6]. Noble metal nanoparticles (NP) have been incorporated in conducting polymers (CPs) using various preparation procedures [7-10]. Usually the NPs are prepared via a chemical route [11-13] and are then incorporated into CP layers by electrochemical polymerization of the appropriate monomer [7] or using the layer-by-layer deposition technique $[14,15]$. Recently, a great deal of interest has been devoted to innovative synthesis route of Pt nanoparticles, for example by the help of ultrasound [16]. Another possibility might lie in the in situ preparation of $\mathrm{Pt}$ nanoparticles achieved via electrochemical methods [17-26]. In situ preparation of Pt nanoparticles has been achieved via electrochemical methods, and in particular potentiostatic deposition at a fixed potential value which is sufficiently negative to assure reduction of the appropriate precursors to metallic states. The reduction of the precursors to metallic states was 
carried out in strong acidic solutions by applying a constant potential for a fixed period of time or by potential cycling in appropriate potential ranges.

The aim of this paper is to demonstrate the suitability of a new in situ electrodeposition preparation procedure based on electrochemical impedance spectroscopy (EIS) technique for Pt nanoparticles deposition on PEDOT coatings. To this purpose, in situ electrochemical preparation of Pt nanoparticles on PEDOT films using sinusoidal voltages of various frequencies is reported here. Use of sinusoidal signals for in situ preparation of Pt nanoparticles is first reported here and is in fact an innovative aspect of this paper in the field of in situ nanoparticles electrodeposition. It is worth to note that the proposed approach is similar to the EIS technique, which makes use of the same materials and method. The use of large amplitude sinusoidal voltages eliminated the possible reduction of proton during the Pt nanoparticles deposition and this resulted in a finer control of the nanoparticles size and roughness of the composite coatings. The resulting composite modified electrodes were investigated in $0.5 \mathrm{M}$ $\mathrm{H}_{2} \mathrm{SO}_{4}$ aqueous solution by cyclic voltammetry $(\mathrm{CV})$, which revealed that $\mathrm{Pt}$ nanoparticles are electrochemically active. The PEDOT-Pt-nanoparticles composite coatings were further characterized by the AFM technique.

\section{Experimental}

\subsection{Chemicals}

All chemicals were used as received without further purification. 3,4ethylenedioxythiophene (EDOT, Aldrich) was used for electrochemical preparation of the corresponding polymer. Deionised water Millipore (18 $\mathrm{M} \Omega \mathrm{cm})$ was used to prepare 
aqueous solutions. Freshly prepared solutions were used for electrochemical measurements.

\subsection{Electrochemical measurements}

The electrochemical experiments were carried out with an Autolab potentiostat/galvanostat 30 (Ecochemie, The Netherlands). A conventional threeelectrode system was used, including a Pt electrode chip as the working electrode, a platinum wire as the auxiliary electrode, and a saturated calomel electrode (SCE) as the reference electrode. All electrochemical measurements were carried out at room temperature, under a high purity nitrogen atmosphere. The platinum electrode chips $\left(0.64 \mathrm{~cm}^{2}\right)$ were fabricated according to a procedure previously reported [27]. Before each electrochemical measurement, the surface of the working electrode was checked by cyclic voltammetry in aqueous solution containing $1 \mathrm{mM} \mathrm{K}_{3} \mathrm{Fe}(\mathrm{CN})_{6}$ and $0.1 \mathrm{M} \mathrm{KCl}$. The impedance spectra were recorded through FRA2 soft of the Autolab potentiostat in the frequency range $0.1 \mathrm{~Hz}-100 \mathrm{kHz}$ using a sinusoidal excitation signal (single sine) with excitation amplitude $\left(\Delta \mathrm{E}_{\mathrm{ac}}\right)$ of $50 \mathrm{mV}$. A variety of frequency domains ranging from $100 \mathrm{kHz}$ to $0.1 \mathrm{~Hz}$ were used for in situ preparation of Pt nanoparticles.

\subsection{Surface analysis of PEDOT-Pt-nanoparticles composite coatings}

Polymer morphology examinations were performed using a commercial Atomic Force Microscope (stand-alone SMENA scanning probe microscope NT-MDT, Russia) in the contact mode. The experiments were conducted in a controlled environment with a laminar flow (humidity $30 \%$ and $25^{\circ} \mathrm{C}$ ). Adhesion of the polymer films was estimated through pull-off measurements. The Si rectangular AFM cantilever, with a stiffness of 
$0.3 \mathrm{~N} / \mathrm{m}$, was fixed, and the substrate moved vertically. Pull-off measurements were taken with a cantilever to which a borosilicate sphere ( $\mathrm{r}=5 \mu \mathrm{m}$ radius $)$ was glued on the free extremity and beneath it (Novascan Technologies, Ames, USA). Consequently, pull-off force represents in this case the adhesion between the borosilicate sphere on the tip AFM cantilever and the substrate. Ten measurements were taken at different points on the same sample with a driving speed of $1 \mu \mathrm{m} / \mathrm{s}$. Roughness of the polymer films was also determined by AFM.

\subsection{In situ electrodeposition of Pt nanoparticles on PEDOT}

The composite PEDOT-Pt-nanoparticles films were prepared by a two-step method. Firstly, the PEDOT layer was electrodeposited from an aqueous solution containing $0.01 \mathrm{M}$ EDOT, and $0.1 \mathrm{M} \mathrm{LiClO}_{4}$ as a supporting electrolyte by potential cycling in the potential range from open-circuit potential, OCP, to +1.0 V/SCE and reversed back to $-0.6 \mathrm{~V} / \mathrm{SCE}$, at a scan rate of $0.05 \mathrm{~V} \mathrm{~s}^{-1}$ for 5 or 10 consecutive scans, respectively. In the second step, in situ deposition of Pt nanoparticles was carried out in $0.001 \mathrm{M}$ $\mathrm{K}_{2} \mathrm{PtCl}_{6}, 0.1 \mathrm{M} \mathrm{HClO}$ aqueous solution by applying the following procedure: sinusoidal voltages of various frequency ranges, i.e. $100 \mathrm{kHz}-0.1 \mathrm{~Hz}, 100-10 \mathrm{kHz}$, with an excitation amplitude $\left(\Delta \mathrm{E}_{\mathrm{ac}}\right)$ of $50 \mathrm{mV}$ were applied at a fixed dc potential value of $-0.20 \mathrm{~V} / \mathrm{SCE}$. The resulting composite modified electrode is referred to as Pt/PEDOT-Pt-nanoparticles.

\section{Results and discussion}

\subsection{Electrodeposition of PEDOT onto Pt electrode chip}


Figures $1 \mathrm{~A}$ and $1 \mathrm{~B}$ show the $\mathrm{CVs}$ recorded during electrochemical deposition of PEDOT coating performed on a naked electrode. Polymerization of the EDOT monomer takes place in the potential range from 0.85 to $1.00 \mathrm{~V} / \mathrm{SCE}$, as can be seen from the increase in anodic current. Growth of the organic PEDOT layer was controlled by the potential cycle number applied in the electrochemical polymerization process, namely 5 (see Fig. 1A) or 10 (see Fig. 1B) consecutive scans.

Figure 1 near here

\subsection{Optimisation of the PEDOT-Pt-nanoparticles composite coatings preparation} procedure

The potentiostatic deposition of $\mathrm{Pt}$ nanoparticles onto PEDOT films is usually performed in strong acidic solutions, at negative potential values, i.e. -0.2 to $-0.3 \mathrm{~V}$. Due to high proton concentration it may be possible that at such negative potential values required for the reduction of platinum precursors to metallic states, the proton reduction can occur simultaneously with the Pt nanoparticles deposition. To this purpose, we investigated the electrochemical behaviour of naked $\mathrm{Pt}$ electrode chips in $0.1 \mathrm{M} \mathrm{HClO}_{4}$ aqueous solution. Figure 2A reports the cyclic voltammograms recorded at Pt electrode in acidic solution. From this figure one can observe that the proton reduction starts at a potential value of ca. $-0.3 \mathrm{~V} / \mathrm{SCE}$. Furthermore, the Pt/PEDOT modified electrode was also investigated by cyclic voltammetry in $0.1 \mathrm{M} \mathrm{HClO}_{4}$ aqueous solution. From Fig. $2 \mathrm{~B}$ it can be seen that there is no proton reduction until a potential value of $-0.3 \mathrm{~V} /$ SCE. Therefore, the deposition potential value used for the in situ electrodeposition of Pt nanoparticles was chosen as -0.2 V/SCE. Once the PEDOT layer was deposited onto 
Pt electrode, the modified electrode was immersed in chloroplatinic acid solution and the preparation procedure, described in Section 2.4, was applied for in situ $\mathrm{Pt}$ nanoparticles electrodeposition on PEDOT films.

Figure 2 near here

\subsection{Preparation of PEDOT-Pt-nanoparticles composite coatings by sinusoidal voltages}

Various sinusoidal voltages were applied for in situ deposition of Pt nanoparticles on PEDOT layer. The duration of the measurements depends on the frequency range used, which resulted in different Pt nanoparticles sizes, that is from $120 \mathrm{~s}$ up to $480 \mathrm{~s}$. Moreover, the amplitude $\left(\Delta \mathrm{E}_{\mathrm{ac}}\right)$ of $50 \mathrm{mV}$ of the sinusoidal excitation signal (single sine) was chosen to allow for the fact that this large amplitude can contribute to fine control of nanoparticles size. Figure 3A reports the impedance spectrum recorded at the Pt/PEDOT modified electrode in chloroplatinic acid solution in the frequency range 100 $\mathrm{kHz}-0.1 \mathrm{~Hz}$. Appearance of a capacitive loop can be observed in the high frequency range of $100-18 \mathrm{kHz}$. This loop is magnified in the inset of Fig. 3A, and should be attributed to the interfacial behaviour between the Pt/PEDOT modified electrode and the solution. Two other loops can be observed in the medium frequency range of $18 \mathrm{kHz}$ $-3 \mathrm{kHz}$ and $3 \mathrm{kHz}-100 \mathrm{~Hz}$. These loops can be associated with Faradaic reactions. These reactions should be the reduction of the precursor $\mathrm{Pt}^{4+}$ complex ions to $\mathrm{Pt}^{2+}$, and then to $\mathrm{Pt}^{0}$ with the formation of $\mathrm{Pt}$ nanoparticles. Finally, at low frequencies, the impedance spectrum is dominated by the Warburg impedance. This impedance spectrum is depicted as Bode plot in Fig. 3B. From the Bode plot one can observe that at low frequencies a slope of -0.8 for $\log \mathrm{Z}$ vs. $\log \mathrm{f}$ was obtained, which is closed to the 
theoretical value of -1 , while for high frequencies a slope close to $\sqrt{3}$, indicative for diffusion-reaction reduced impedance, is obtained. Furthermore, the phase vs. log f plot depicted in Fig. 3B shows that at low frequencies a phase of ca. 80 degrees is obtained, while for high frequencies the phase tends to zero, which is indicative of capacitive behaviour. A value of ca. $78 \mathrm{Ohms}$ for the charge transfer resistance $\left(\mathrm{R}_{\mathrm{ct}}\right)$ can be obtained from the Z' vs. $1 / \omega^{2}$ plot, which is depicted in Fig. 3 C. From this value, the exchange current density $\left(i_{0}\right)$ was determined as $1.29 \times 10^{-4} \mathrm{~A} \mathrm{~cm}^{-2}$, according to the equation (1):

$$
R_{c t}=R T /\left(n F i_{0}\right)
$$

where $\mathrm{n}=4$, and the other symbols have their usual significance [28].

Therefore, it is worth to note that the new preparation procedure allows for the electrochemical parameters, such as charge transfer resistance and exchange current density, to be also determined. This feature is brought by the EIS powerful technique used in the Pt nanoparticles electrodeposition and can be considered as an advantageous tool compared with the classical potentiostatic methods applied for nanoparticles deposition.

Figure 3 near here

\subsection{Electrochemical characterization of PEDOT-Pt-nanoparticles composite materials}

After deposition of $\mathrm{Pt}$ nanoparticles onto the PEDOT layer, the modified electrodes were characterized in $0.5 \mathrm{M} \mathrm{H}_{2} \mathrm{SO}_{4}$ aqueous solution using cyclic voltammetry. Figure 4 reports the cyclic voltammograms recorded for various types of PEDOT-Ptnanoparticles coatings prepared on different experimental parameters, i.e. the frequency 
range, the number of measured frequencies, and the number of deposition scans applied in the preparation procedure of the PEDOT coatings. Two well-separated pairs of peaks can be observed between -0.25 and $0.0 \mathrm{~V} / \mathrm{SCE}$, which are due to adsorption and desorption of hydrogen atoms on Pt nanoparticles surfaces. Pt oxide formation occurred in the potential range from $0.8 \mathrm{~V}$ to $1.0 \mathrm{~V} / \mathrm{SCE}$, and the corresponding reduction peak of Pt oxide is located at $0.6 \mathrm{~V} / \mathrm{SCE}$. The features of the voltammograms were similar to the polycrystalline Pt electrode, with typical peaks at $-0.13 \mathrm{~V}$ and $-0.05 \mathrm{~V} / \mathrm{SCE}$, whereas the pure PEDOT the current is low and only influence by its capacitance. The peak currents for the reduction waves located in the potential range $-0.25-0.0 \mathrm{~V} / \mathrm{SCE}$ increased with deposition time corresponding to different frequency ranges and the number of measured frequencies used in the preparation procedure.

It is important to notice the drastic increase in the anodic peaks, which rose from $2.6 \mu \mathrm{A}$ at $-0.05 \mathrm{~V}$ for naked $\mathrm{Pt}$ up to $126 \mu \mathrm{A}$ at $-0.05 \mathrm{~V} / \mathrm{SCE}$, maximum met for nanoparticles deposited by a sinusoidal voltage $(100 \mathrm{kHz}-0.1 \mathrm{~Hz}, 50$ frequencies, on PEDOT deposited by 5 scans). These results demonstrate that Pt nanoparticles deposited on PEDOT coating by a sinusoidal voltage were electrochemically active. By comparison, nanoparticles prepared by classical potentiostatic methods, deposition time $1200 \mathrm{~s}$ [22], give electrodes with a similar behaviour.

The electrochemically active surface area can be estimated by using the characteristic value of the charge density for a monolayer of hydrogen adsorbed on polycrystalline platinum electrode, i.e. $0.21 \mathrm{mC} \mathrm{cm}^{-2}[23,29-31]$. The cyclic voltammograms presented in Fig. 4 indicate that the PEDOT-Pt-nanoparticles composite, deposited by a sinusoidal voltage with a frequency range of $0.1 \mathrm{~Hz}-100$ $\mathrm{kHz}, 50$ frequencies, has the largest active surface area $\left(5.16 \mathrm{~cm}^{2}\right)$ compared with other 
composite coatings prepared in this work and those previously reported [23]. The values of the estimated electroactive surface area for the Pt nanoparticles composite coatings are presented in Table 1.

Figure 4 near here

Table 1 near here

The thickness of the PEDOT layer influences the electrodeposition of $\mathrm{Pt}$ nanoparticles as can be seen from Fig. 4 on the CV trace for a PEDOT coating obtained by applying 10 consecutive deposition scans. In this case the increased thickness of the PEDOT layer hindered the formation of Pt nanoparticles and as a result the hydrogen adsorption-desorption peaks are not well defined. Therefore, an extended frequency range and/or a larger number of measured frequencies should be used for the $\mathrm{Pt}$ nanoparticles electrodeposition by sinusoidal voltages when thicker PEDOT coatings are involved. The increased numbers of deposition scans used in the electropolymerization of the EDOT monomer resulted in an enhanced surface area of the electrode, as can be seen from Table 1, but the adsorption/desorption hydrogen peaks are not well defined. Furthermore, the Pt electrode modified with a pure PEDOT coating shows no peaks in the potential range from -0.25 to $0.0 \mathrm{~V} / \mathrm{SCE}$ and this result supports the above findings concerning the electrochemical activity of the $\mathrm{Pt}$ nanoparticles.

\subsection{Surface analysis of the PEDOT-Pt-nanoparticles composite coatings}


2D and 3D AFM images were performed on PEDOT-LiClO 4 films (Figures 5A and 5B) and on PEDOT-Pt-nanoparticles composite films obtained by a sinusoidal voltage in chloroplatinic acid solution at a fixed potential value of $-0.20 \mathrm{~V} / \mathrm{SCE}$ for the frequency

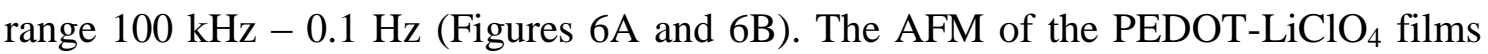
exhibited a granular, regular and homogeneous structure. Grain size is less than $200 \mathrm{~nm}$ and height can be estimated at $80-90 \mathrm{~nm}$.

Figure 5 near here

On the contrary, the PEDOT-Pt-nanoparticles films have a slightly different structure since the surface showed a rougher relief, with a strong increase in heterogeneities. This change of topography is due to the nanoparticles inserted in the polymer film. The nanoparticles thus led to an increase in film roughness, and the height of the grains growing on the nanoparticles can be estimated at $270 \mathrm{~nm}$. Therefore, one can assume that the nanoparticles size is approximately $170-180 \mathrm{~nm}$.

Figure 6 near here

The adhesion force, known as the "pull-off force", was measured for all polymer coatings versus their electrodeposition conditions (with or without deposition of nanoparticles). The pull-off values are presented in Table 2.

Table 2 near here 
The results presented in this table show marked differences in the adhesion forces between PEDOT-LiClO 4 and PEDOT-Pt-nanoparticles samples. Indeed, PEDOT$\mathrm{LiClO}_{4}$ exhibited an attractive pull-off force of $-40.4 \mathrm{nN}$. On the contrary, the pull-off force was only included in the range between -5 and $-15 \mathrm{nN}$, indicating a marked modification in surface properties and proving once again the presence of $\mathrm{Pt}$ nanoparticles. Moreover, the less negative pull-off values $(-3.79$ and $-5.13 \mathrm{nN})$ were obtained with the thickest films (obtained through 50 frequencies instead of 5 or 10 for the two other samples), confirming that the presence of Pt nanoparticles influences the adhesion properties of the films.

\subsection{Advantages of the novel reported preparation procedure}

The presented results clearly show that the in situ electrodeposition of Pt nanoparticles by using sinusoidal voltages offer some advantages compared with the potentiostatic method. First of all, the novel procedure provides a finer control of the nanoparticles size and especially of the surface roughness of the composite coatings. Values of the roughness ranging from $880 \mathrm{~nm}$ to $1.6 \mu \mathrm{m}$ were obtained depending on the time of deposition of the nanoparticles Moreover, by applying a sinusoidal voltage over the dc fixed voltage of $-0.2 \mathrm{~V} / \mathrm{SCE}$ in acidic media the proton reduction was totally hindered thanks to the large amplitude of the sinusoidal voltage of $50 \mathrm{mV}$, even if it is shown that under these experimental conditions the proton reduction starts at ca. $-0.3 \mathrm{~V} / \mathrm{SCE}$ (see Fig. 2A). The large amplitude of the sinusoidal voltage used in this work prevented the agglomeration of Pt nanoparticles and the proton reduction, resulting in a smaller size of Pt nanoparticles and roughness values. The use of various frequencies pointed out that the optimum range is $0.1 \mathrm{~Hz}-100 \mathrm{kHz}$. When the same number of frequencies was 
employed, the peak currents were higher for the $0.1 \mathrm{~Hz}-100 \mathrm{kHz}$ range in comparison with $10-100 \mathrm{kHz}$ range, noting that the duration of the measurement was almost the same. Furthermore, the peak currents of the adsorption / desorption of hydrogen are comparable with those reported in Ref. 22, where the Pt nanoparticles were deposited by potentiostatic method at $-0.2 \mathrm{~V}$ in $1.1 \mathrm{mM} \mathrm{H}_{2} \mathrm{PtCl}_{6}, 0.5 \mathrm{M} \mathrm{H}_{2} \mathrm{SO}_{4}$ solution for a deposition time of $1200 \mathrm{~s}$, which is 2.5 times higher in respect to the time used for the Pt nanoparticles deposition by a sinusoidal voltage with a frequency range of $0.1 \mathrm{~Hz}-$ $100 \mathrm{kHz}$. Therefore, it can be concluded that the use of sinusoidal voltages in $\mathrm{Pt}$ nanoparticles in situ electrodeposition provides a better control of the nanoparticles size and surface roughness. Finally, it is worth to note that this new in situ preparation procedure allows the estimation of the electrochemical parameters, such as charge transfer resistance and exchange current density. This feature is brought by the EIS powerful technique used in the Pt nanoparticles in situ electrodeposition and can be considered as an appealing advantage compared with the classical potentiostatic methods applied for metal nanoparticles deposition.

\section{Conclusions}

Pt nanoparticles were successfully electrodeposited in situ, for the first time, on PEDOT organic conductive polymers using sinusoidal voltages of various frequencies in a chloroplatinic acid solution. The cyclic voltammograms recorded in $0.5 \mathrm{M} \mathrm{H}_{2} \mathrm{SO}_{4}$ aqueous solution demonstrated that Pt nanoparticles deposited via this novel preparation procedure are electrochemically active. Values of the roughness ranging from $880 \mathrm{~nm}$ to $1.6 \mu \mathrm{m}$ were obtained depending on the time of deposition of the nanoparticles. This 
novel in situ preparation procedure provides PEDOT-Pt-nanoparticles composite electrode with a large active surface area $\left(5.16 \mathrm{~cm}^{2}\right)$ compared with other composite coatings previously reported. The AFM measurements revealed the presence of numerous deposited Pt nanoparticles on the organic PEDOT polymer film. The novel reported method for Pt nanoparticles in situ electrodeposition on conducting polymer films provides a better control of the nanoparticles size and surface roughness. This work thus proposes a novel and efficient strategy for in situ electrochemical deposition of Pt nanoparticles on an organic conductive polymer matrix.

\section{Acknowledgements}

S. Lupu greatly acknowledges the Invited Professor stage at the University of FrancheComté, France. Authors gratefully thank the MIMENTO platform of the FEMTO-ST Institute in Besançon, France.

\section{REFERENCES}

[1] J. Wang, Anal. Chim. Acta 500 (2003) 247-257.

[2] X. Luo, A. Morrin, A.J. Killard, M.R. Smyth, Electroanalysis 18 (2006) 319326.

[3] S. Guo, S. Dong, Trends Anal. Chem. 28 (2009) 96-109.

[4] M. Sastry, Pure Appl. Chem. 74 (2002) 1621-1630.

[5] C.M. Welch, R.G. Compton, Anal. Bioanal. Chem. 384 (2006) 601-619.

[6] F.W. Campbell, R.G. Compton, Anal. Bioanal. Chem. 396 (2010) 241-259.

[7] A. Nirmala Grace, K. Pandian, Electrochem. Commun. 8 (2006) 1340-1348.

[8] K. Bouzek, K.-M. Mangold, K. Jüttner, Electrochim. Acta 46 (2001) 661-670. 
[9] S. Senthil Kumar, J. Mathiyarasu, K. Lakshminarasimha Phani, J. Electroanal. Chem. 578 (2005) 95-103.

[10] K.M. Manesh, P. Santhosh, A. Gopalan, K.P. Lee, Talanta 75 (2008) 13071314.

[11] K.E. Christodoulakis, D. Palioura, S.H. Anastasiadis, M. Vamvakaki, Top Catal. 52 (2009) 394-411.

[12] Q.Y. Deng, B. Yang, J.F. Wang, C.G. Whiteley, X.N. Wang, Biotechnol. Lett. 31 (2009) 1505-1509.

[13] B. Qu, Y.-T. Xu, S. Lin, Y.-F. Zheng, L.-Z. Dai, Synth. Met. 160 (2010) 732742.

[14] K. Karnicka, M. Chojak, K. Miecznikowski, M. Skunik, B. Baranowska, A. Kolary, A. Piranska, B. Palys, L. Adamczyk, P.J. Kulesza, Bioelectrochemistry 66 (2005) 79-87.

[15] P.J. Kulesza, K. Karnicka, K. Miecznikowski, M. Chojak, A. Kolary, P.J. Barczuk, G. Tsirlina, W. Czerwinski, Electrochim. Acta 50 (2005) 5155-5162.

[16] B.G. Pollet, Int. J. Hydrogen Energy 35 (2010) 11986-12004.

[17] Y. Liu, M. Yang, Z. Zheng, B. Zhang, Electrochim. Acta 51 (2005) 605-610.

[18] F. Maillard, E.R. Savinova, U. Stimming, J. Electroanal. Chem. 599 (2007) 221-232.

[19] C.W. Kuo, C. Sivakumar, T.-C. Wen, J. Power Sources 185 (2008) 807-814.

[20] S. Patra, N. Munichandraiah, Langmuir 25 (2009) 1732-1738.

[21] V. Zin, B.G. Pollet, M. Dabalà, Electrochim. Acta 54 (2009) 7201-7206.

[22] L.Y. Bian, Y.H. Wang, J.B. Zang, J.K. Yu, H. Huang, J. Electroanal. Chem. 644 (2010) 85-88. 
[23] Y. Zhou, H. Xian, F. Li, S. Wu, Q. Lu, Y. Li, L. Wang, Electrochim. Acta 55 (2010) 5905-5910.

[24] C. Sivakumar, Electrochim. Acta 52 (2007) 4182-4190.

[25] T. Spataru, M. Marcu, A. Banu, E. Roman, N. Spataru, Electrochim. Acta 54 (2009) 3316-3319.

[26] D.-M Zeng, Y.-X Jiang, Z.-Y Zhou, Z.-F Su, S.-G Sun, Electrochim. Acta 55 (2010) 2065-2072.

[27] O. Segut, B. Lakard, G. Herlem, J.Y. Rauch, J.C. Jeannot, L. Robert, B. Fahys, Anal. Chim. Acta 597 (2007) 313-321.

[28] A.J. Bard, L.R. Faulkner, Electrochemical Methods, Wiley, New York, 1980.

[29] S. Trasatti, O.A. Petrii, Pure Appl. Chem. 63 (1991) 711-734.

[30] K. Shimazu, D.Weisshaar, T. Kuwana, J. Electroanal. Chem. 223 (1987) 223234.

[31] Y. Xu, X. Lin, J. Power Sources 170 (2007) 13-19. 


\section{Captions to figures}

Fig. 1. Cyclic voltammograms recorded during electrochemical polymerization of EDOT at the Pt electrode chip in an aqueous solution containing 0.01 M EDOT and 0.1 $\mathrm{M} \mathrm{LiClO}_{4}$ as a supporting electrolyte. Potential scan rate: $0.05 \mathrm{~V} \mathrm{~s}^{-1}$. The first 5 (A) and 10 (B) consecutive scans are depicted, respectively.

Fig. 2. Cyclic voltammograms recorded at (A) Pt naked electrode chip and (B) $\mathrm{Pt} / \mathrm{PEDOT}$ modified electrode in $0.1 \mathrm{M} \mathrm{HClO}_{4}$ aqueous solution at a potential scan rate of $0.05 \mathrm{~V} \mathrm{~s}^{-1}$.

Fig. 3. (A) Impedance spectrum recorded on Pt/PEDOT modified electrode at a fixed dc potential value of $-0.2 \mathrm{~V}$ for frequency range from $100 \mathrm{kHz}$ to $0.1 \mathrm{~Hz}$ in an aqueous solution containing $0.001 \mathrm{M} \mathrm{K}_{2} \mathrm{PtCl}_{6}$ and $0.1 \mathrm{M} \mathrm{HClO}_{4}$. (B) The Bode plot and (C) the Z', Z' vs. $1 / \omega^{2}$ plot of the impedance spectrum obtained as described in Fig. 3A.

Fig. 4. Cyclic voltammograms recorded at Pt/PEDOT-Pt-nanoparticles composite modified electrodes and naked Pt electrode in $0.5 \mathrm{M} \mathrm{H}_{2} \mathrm{SO}_{4}$ aqueous solution at a scan rate of $0.05 \mathrm{~V} \mathrm{~s}^{-1}$.

Fig. 5. (A) 2D and (B) 3D AFM images (contact mode) of PEDOT films obtained through 5 cycles. 
Fig. 6. (A) 2D and (B) 3D AFM images (contact mode) of Pt-nanoparticles prepared in situ on PEDOT film at a fixed potential value of $-0.20 \mathrm{~V}$ for frequency range from 100 $\mathrm{kHz}$ to $0.1 \mathrm{~Hz}$ (5 deposition cycles for PEDOT matrix, 50 frequencies).

\section{Table 1}

The estimation of the electrochemically active surface areas of the polymer composite modified electrodes.

Table 2

Estimation of the pull-off values, using AFM, of the polymer films in the presence or absence of nanoparticles. 
Table 1. The estimation of the electrochemically active surface areas of the polymer composite modified electrodes.

\section{Composite electrode}

Electrochemically active

surface area $\left(\mathrm{cm}^{2}\right)$

PEDOT - $\mathrm{LiClO}_{4}$ (5 scans) -Pt nanoparticles deposited by a sinusoidal voltage, $\Delta \mathrm{F}=100 \mathrm{kHz}-0.1 \mathrm{~Hz}, 50$ frequencies

PEDOT - $\mathrm{LiClO}_{4}$ (5 scans) - Pt nanoparticles deposited by a sinusoidal voltage, $\Delta \mathrm{F}=100 \mathrm{kHz}-10 \mathrm{kHz}, 50$ frequencies

PEDOT - $\mathrm{LiClO}_{4}$ (5 scans) - Pt nanoparticles deposited by a sinusoidal voltage, $\Delta \mathrm{F}=100 \mathrm{kHz}-10 \mathrm{kHz}, 10$ frequencies

PEDOT - $\mathrm{LiClO}_{4}$ (10 scans) - Pt nanoparticles deposited by a sinusoidal voltage, $\Delta \mathrm{F}=100 \mathrm{kHz}-10 \mathrm{kHz}, 10$ frequencies. 
Table 2. Estimation of the pull-off values, using AFM, of the polymer films in the presence or absence of nanoparticles.

Sample

PEDOT - $\mathrm{LiClO}_{4} 5$ scans

PEDOT - $\mathrm{LiClO}_{4}$ (5 scans) -Pt nanoparticles deposited by a sinusoidal voltage, $\Delta \mathrm{F}=100 \mathrm{kHz}-0.1 \mathrm{~Hz}, 50$ frequencies

PEDOT - $\mathrm{LiClO}_{4}$ (5 scans) - Pt nanoparticles deposited by a sinusoidal voltage, $\Delta \mathrm{F}=100 \mathrm{kHz}-10 \mathrm{kHz}, 50$ frequencies

PEDOT - $\mathrm{LiClO}_{4}$ (5 scans) - Pt nanoparticles deposited by a sinusoidal voltage, $\Delta \mathrm{F}=100 \mathrm{kHz}-10 \mathrm{kHz}, 10$ frequencies

PEDOT - $\mathrm{LiClO}_{4}$ (10 scans) - Pt nanoparticles deposited by a sinusoidal voltage, $\Delta \mathrm{F}=100 \mathrm{kHz}-10 \mathrm{kHz}, 10$ frequencies. PEDOT- $\mathrm{LiClO}_{4}$ (10 scans) - Pt nanoparticles deposited by a sinusoidal voltage, $\Delta \mathrm{F}=100 \mathrm{kHz}-10 \mathrm{kHz}, 5$ frequencies.

\section{Pull-off (nN)}

$-40.4$ 


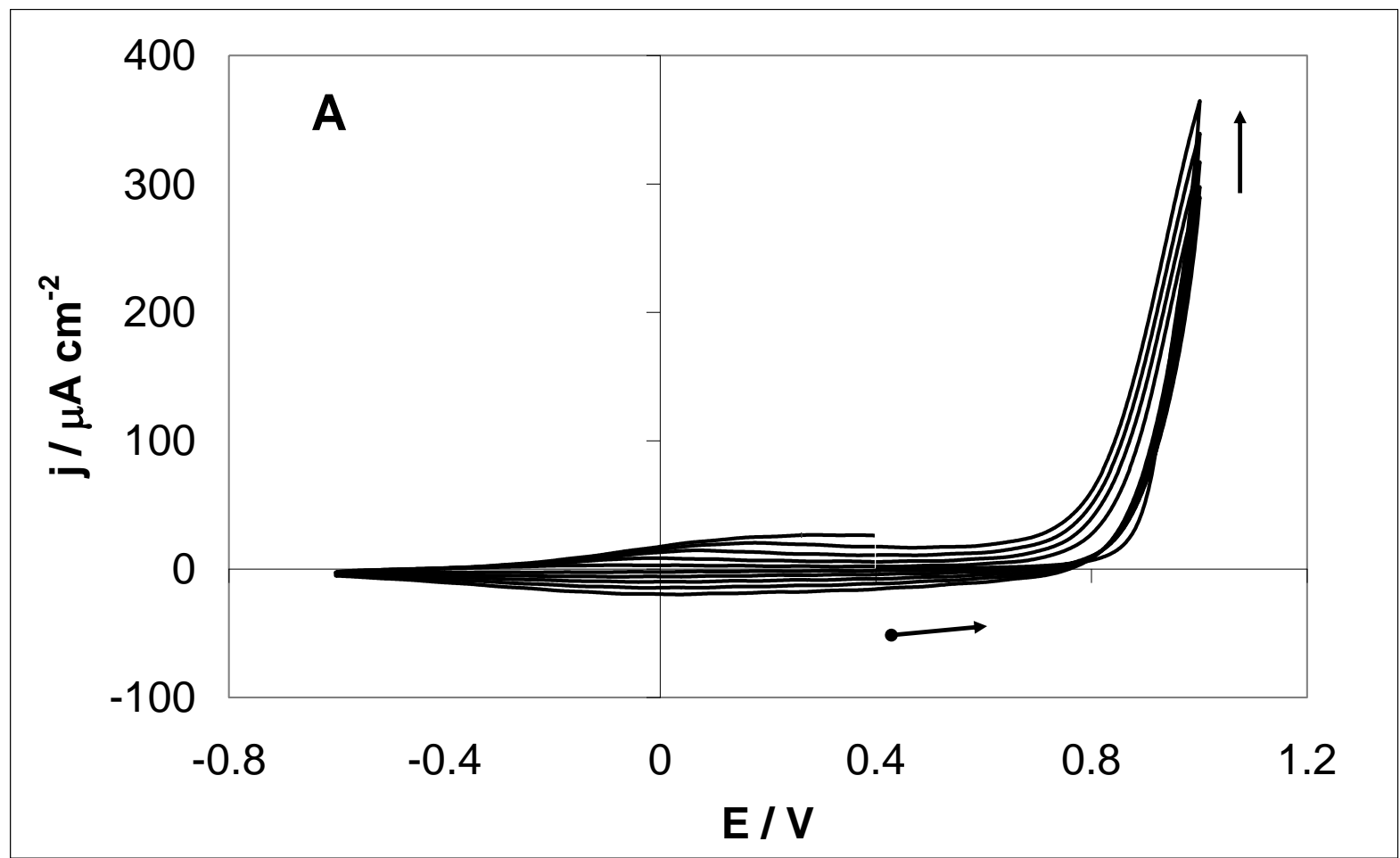

Figure 1A. 
Figure-1B

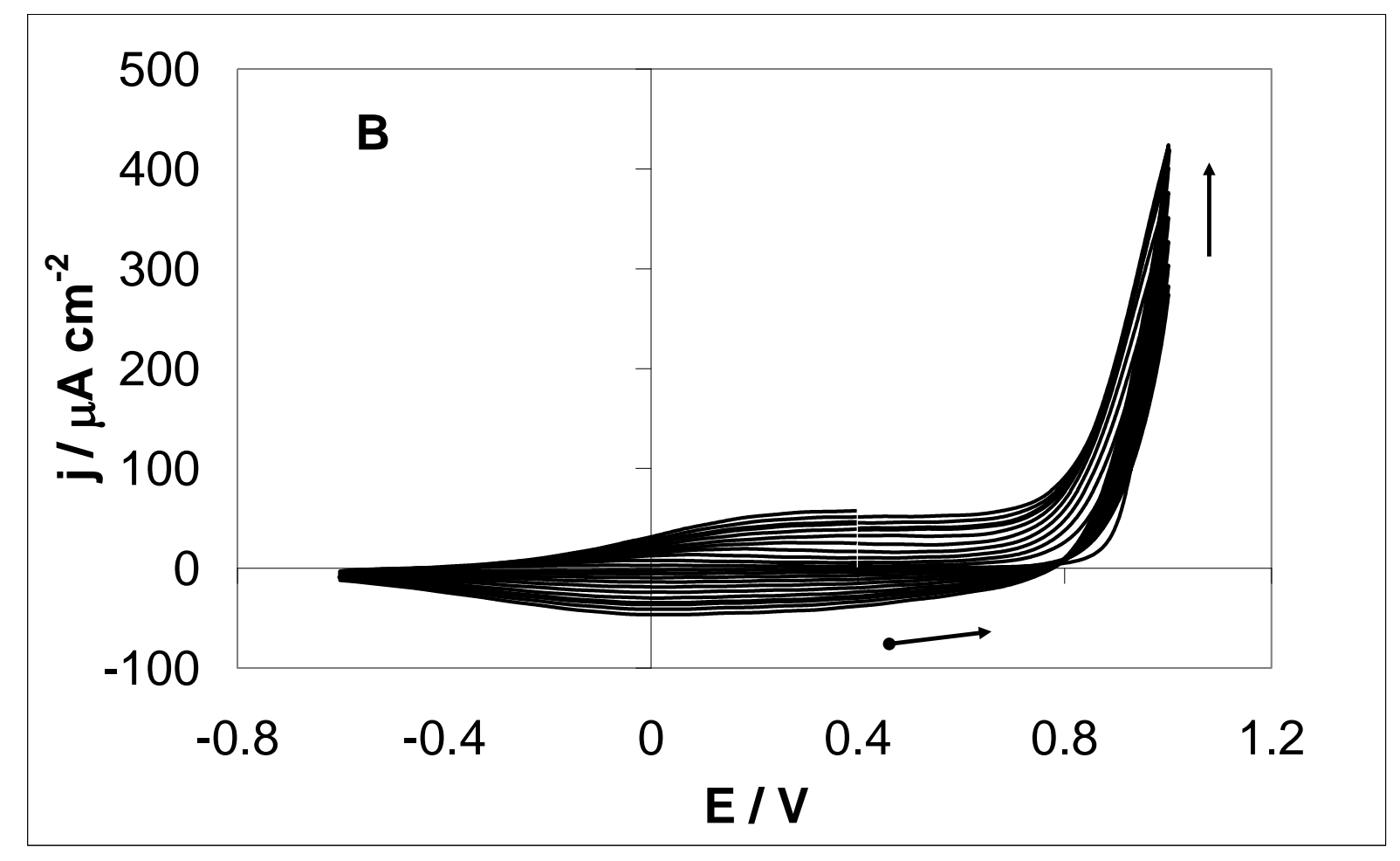

Figure 1B. 
Figure-2A

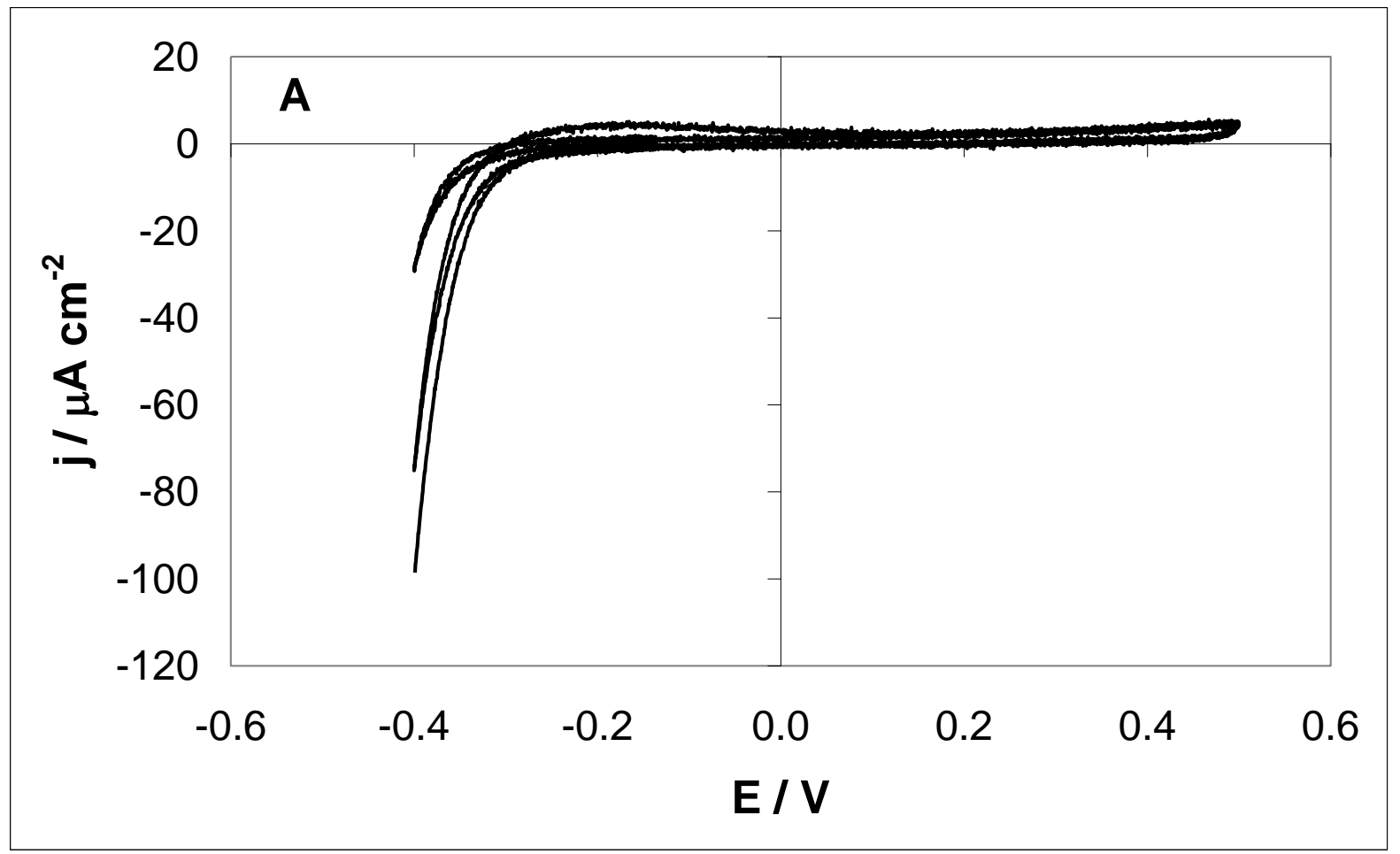

Figure 2A. 
Figure-2B

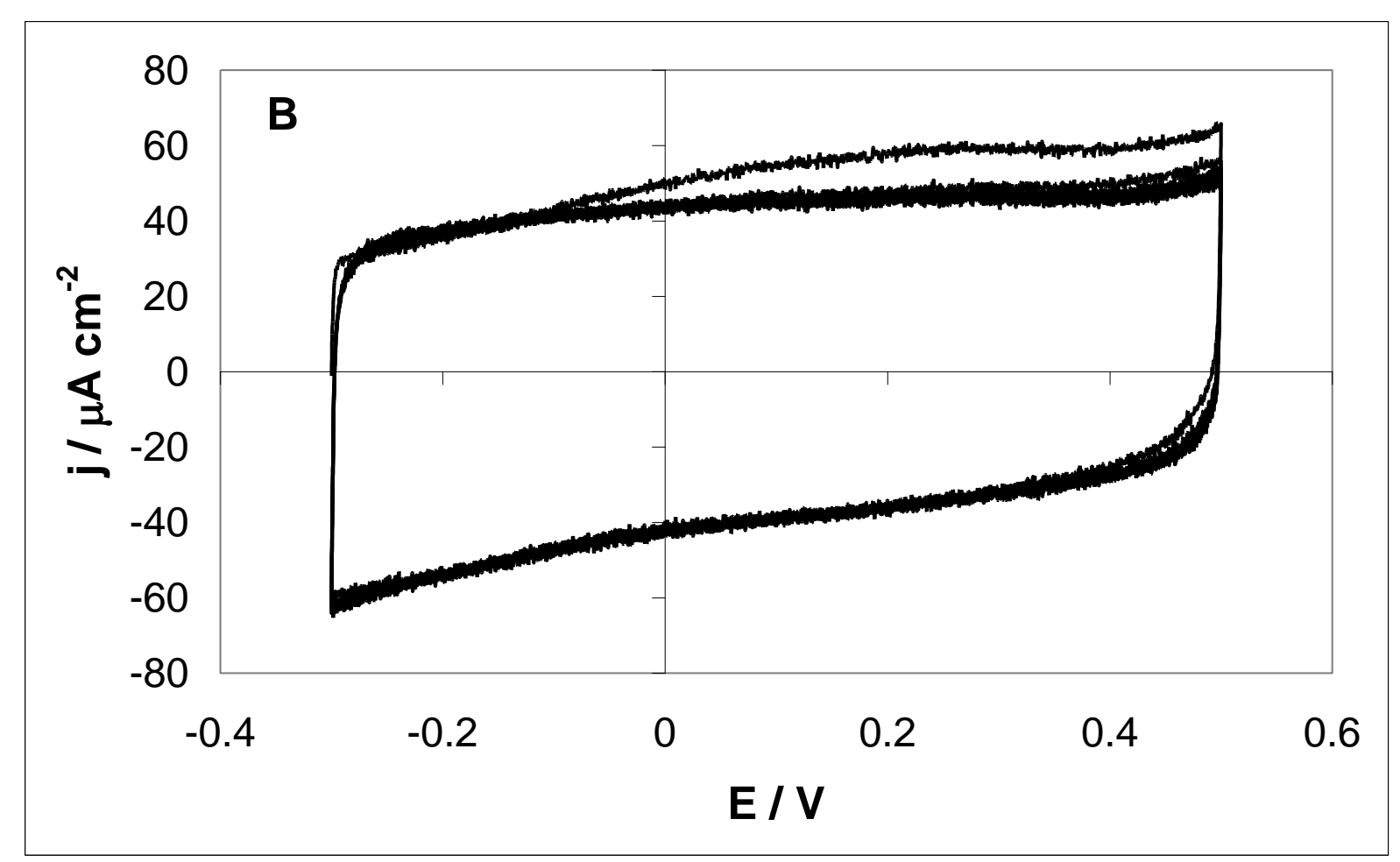

Figure 2B. 


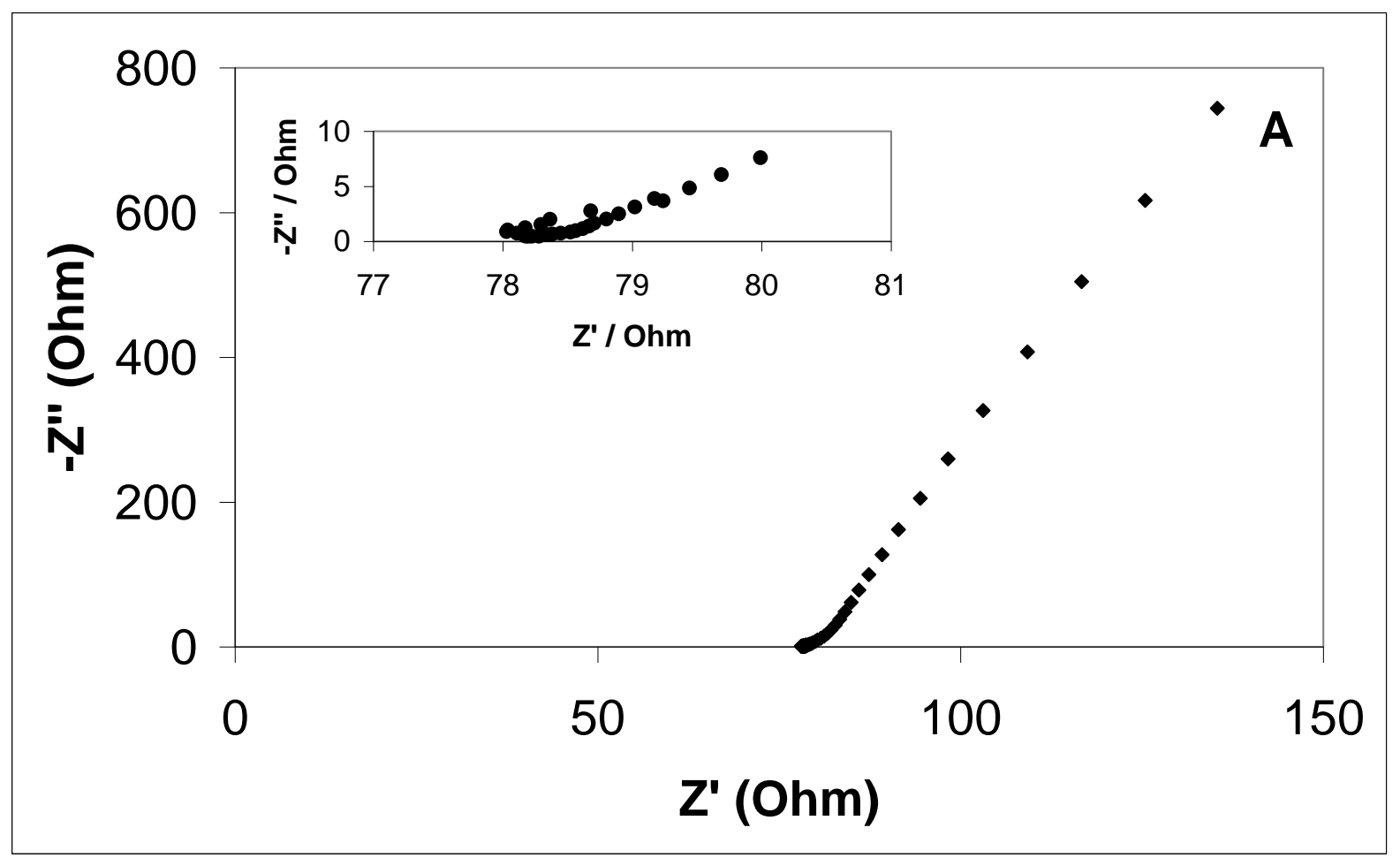

Figure 3A. 


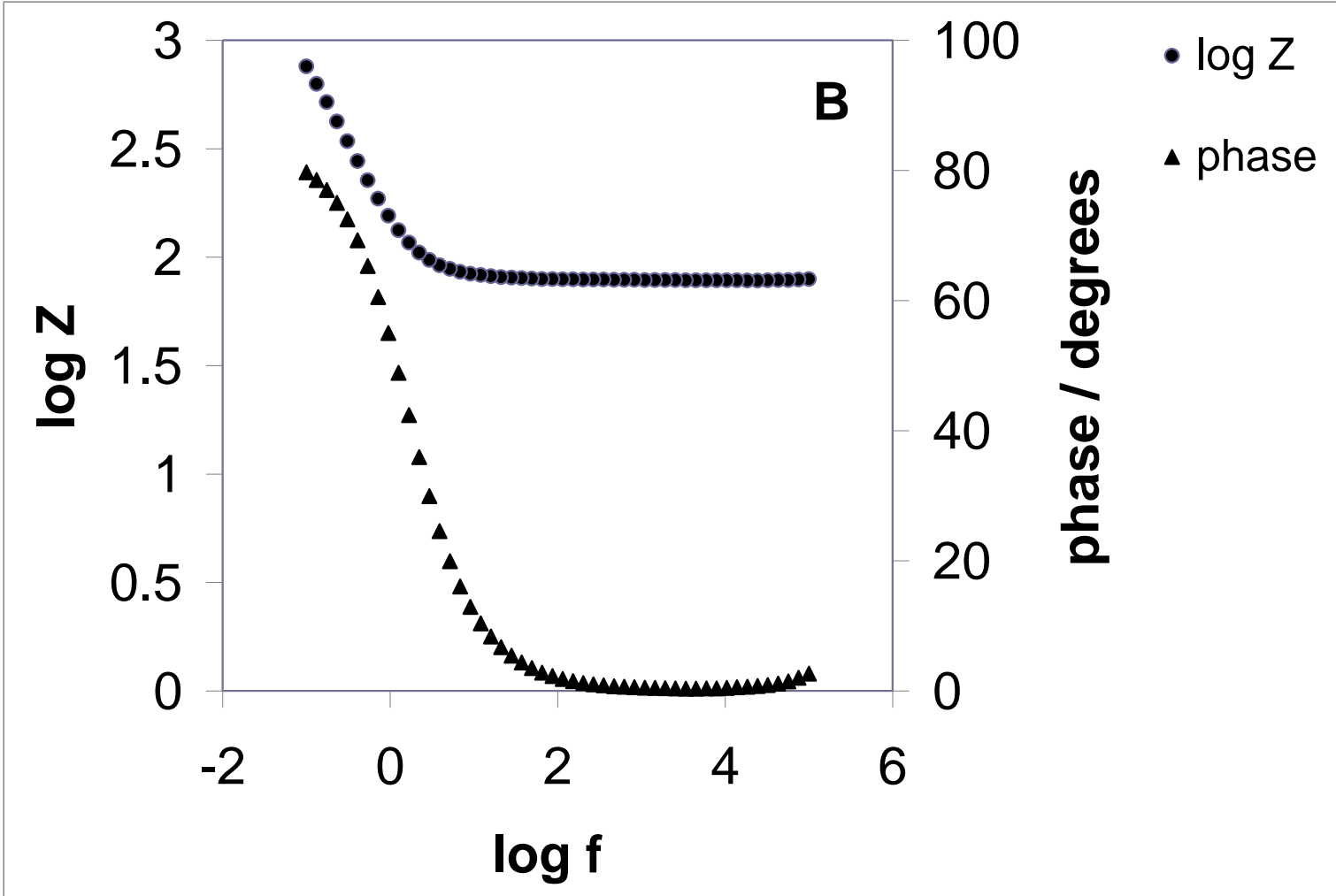

Figure 3B. 
Figure-3C

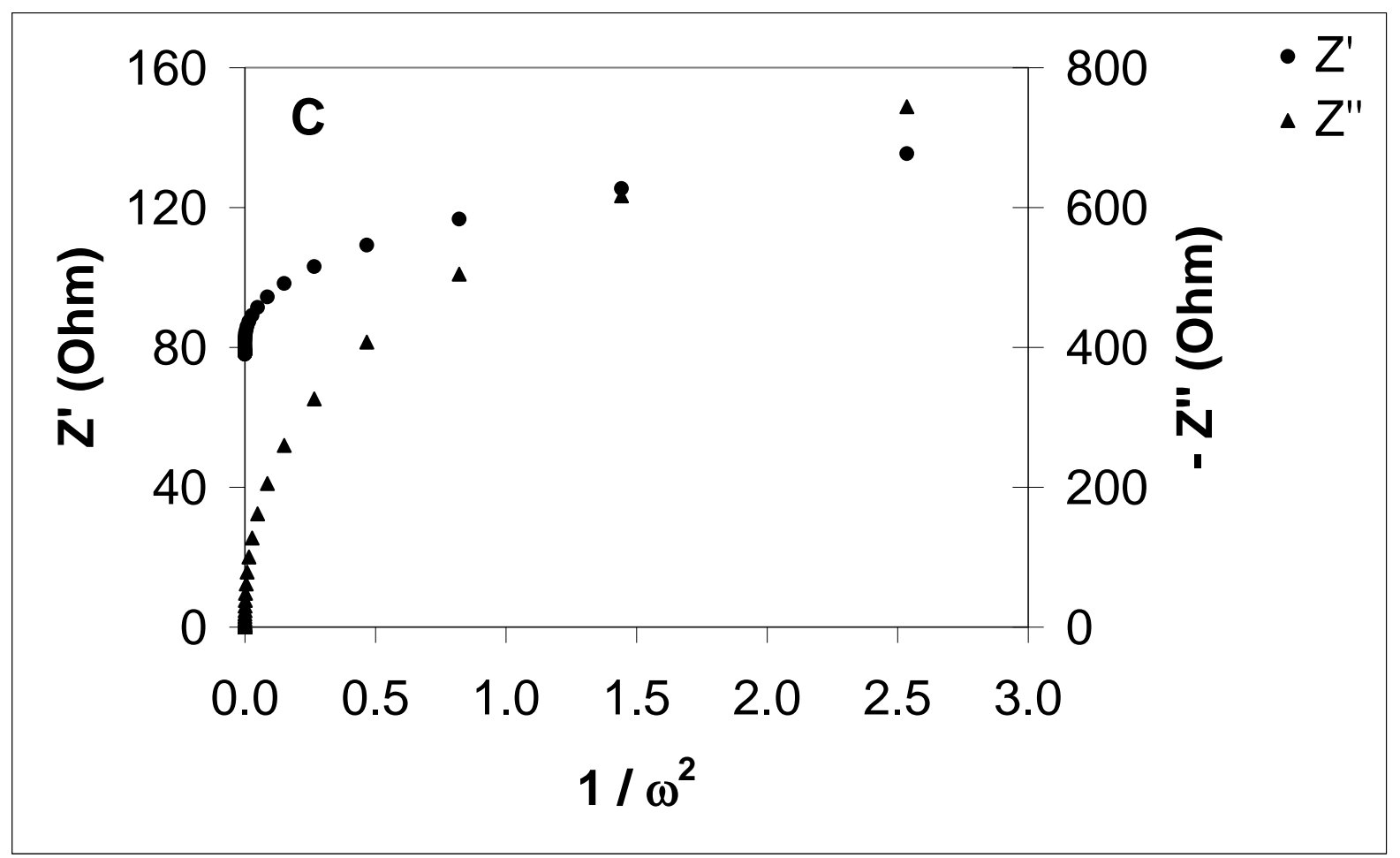

Figure 3C. 


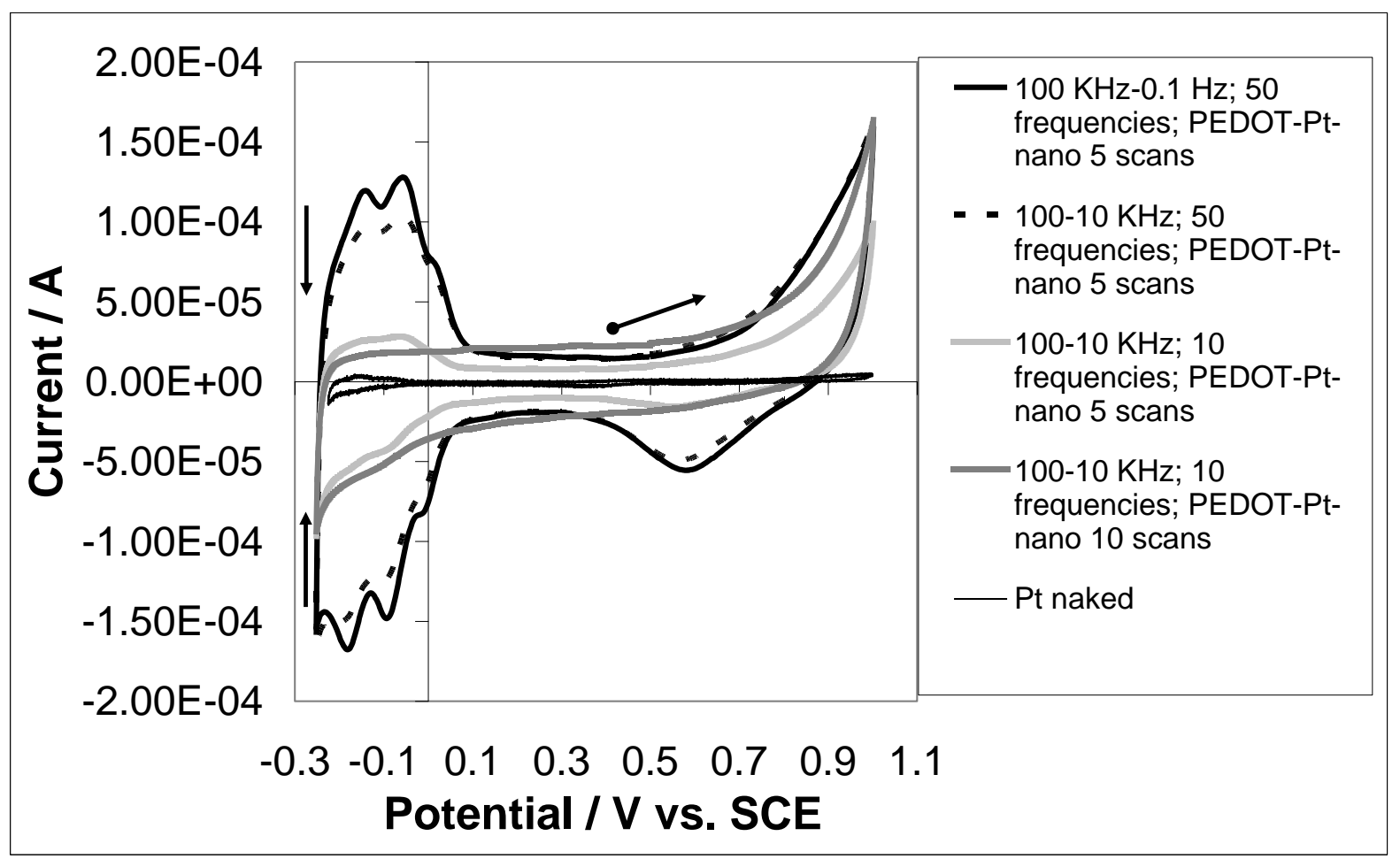

Figure 4. 
Figure-5A

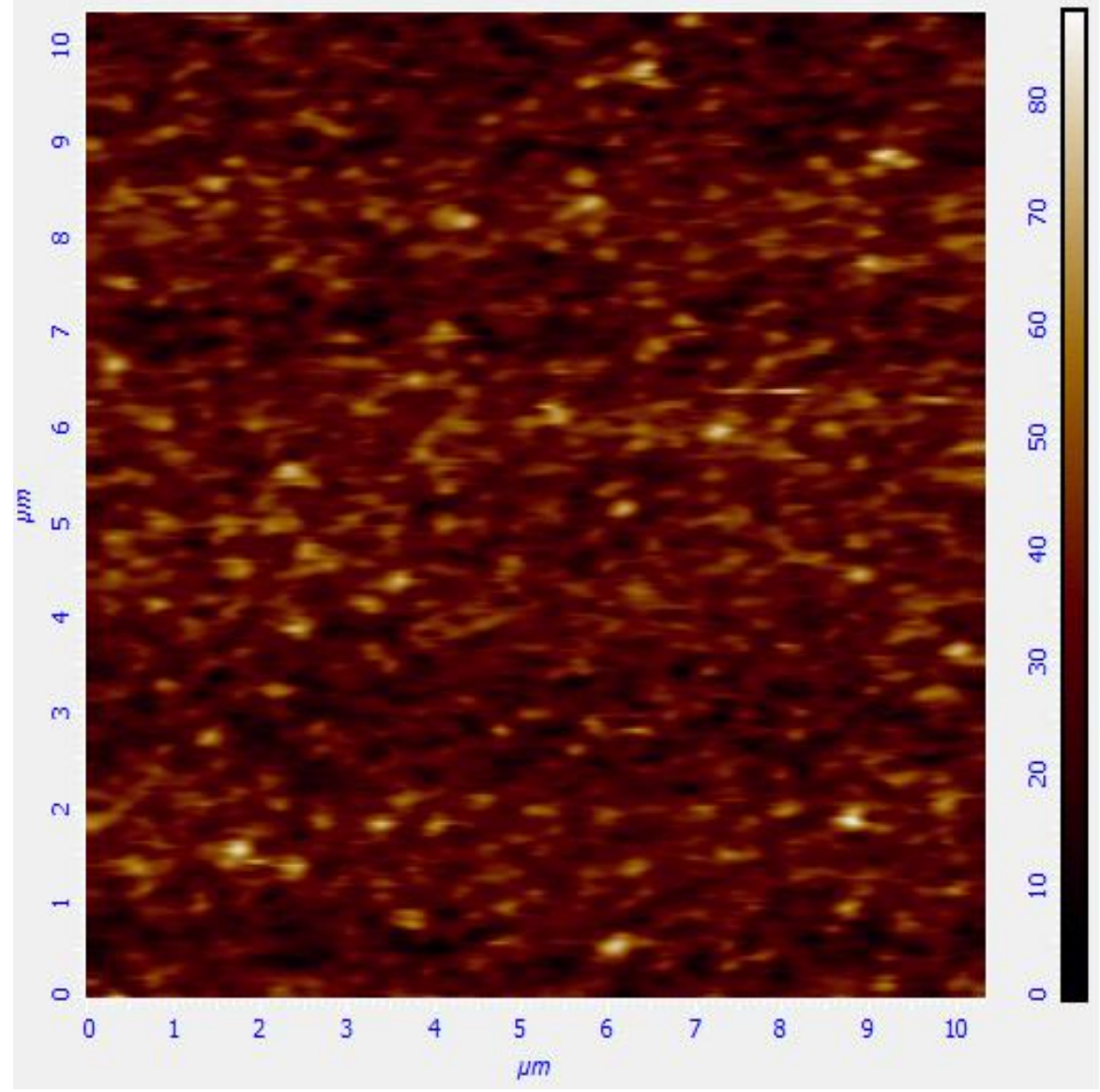

Figure 5A. 
Figure-6A

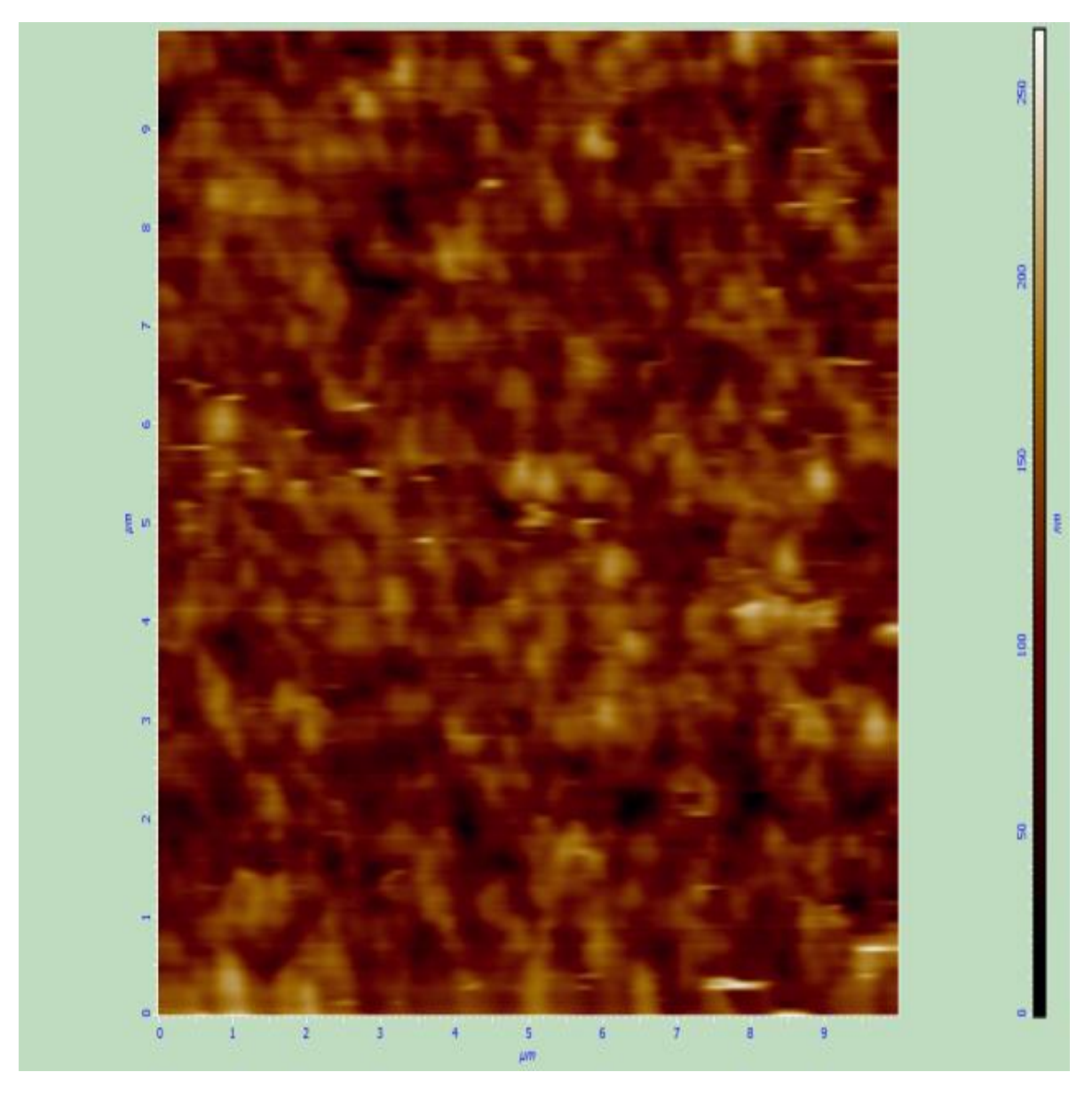

Figure 6A.

Figure-6A

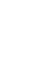

.
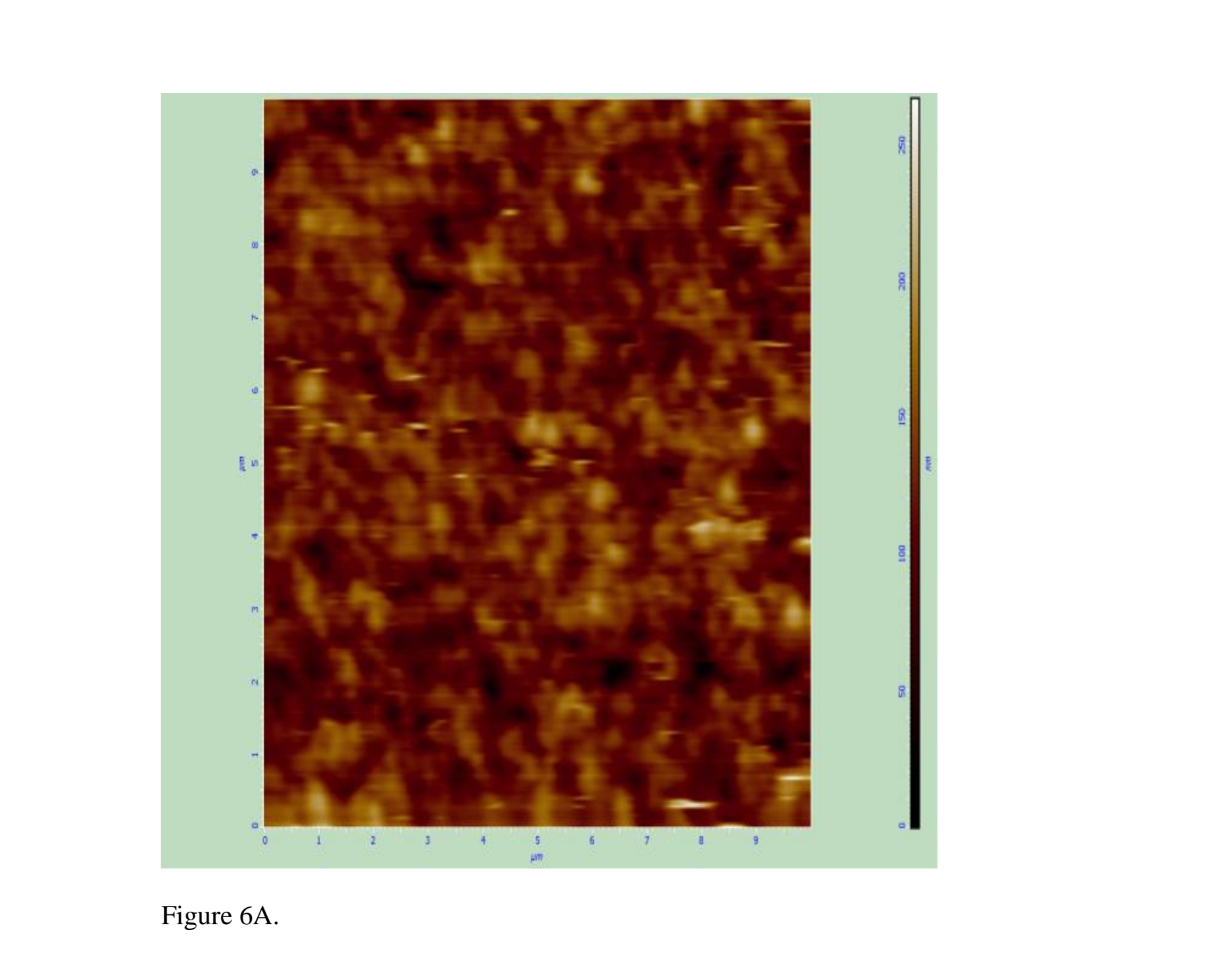


\section{Figure-6B}

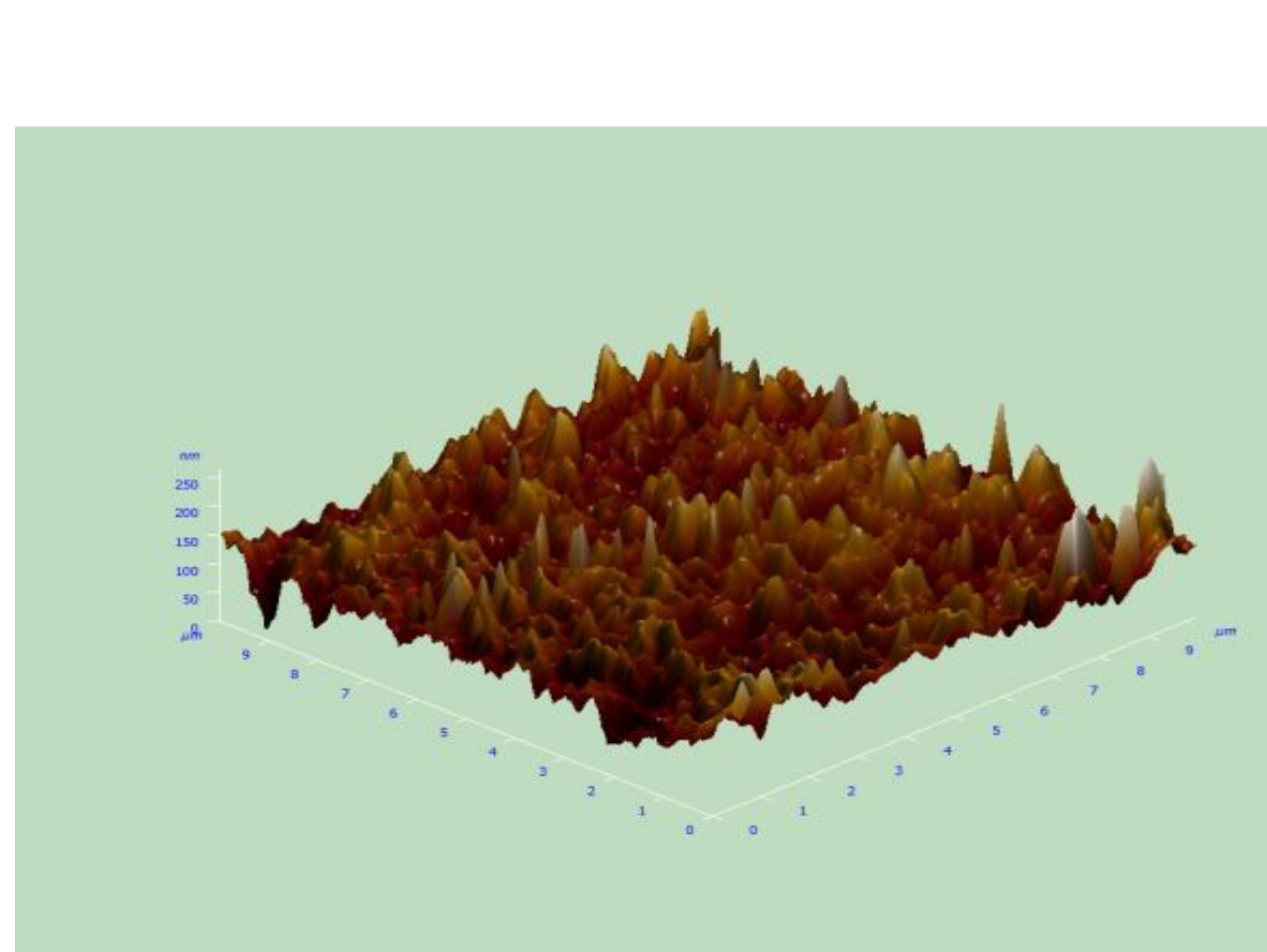

Figure 6B.

2

.

(n)

(2)

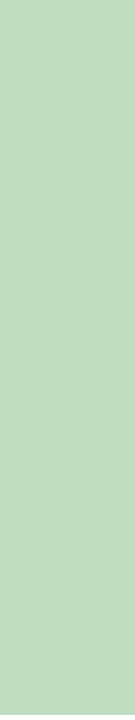

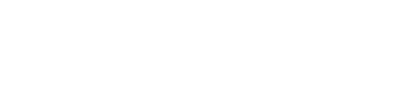

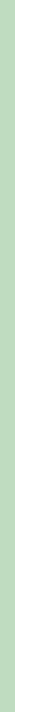

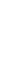
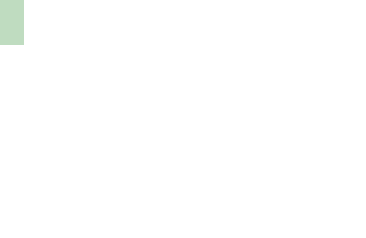